declared, Maria Rita Gigante: None declared, Clara Di Mario: None declared, Luca Petricca: None declared, Andrew Filer: None declared, Neal L Millar: None declared, Elisa Gremese Consultant for: AbbVie, BMS, Celgene, Janssen, Lilly, MSD, Novartis, Sanofi, UCB, Roche, and Pfizer, Speakers bureau: BMS, Speakers bureau: Roche, Speakers bureau: AbbVie, BMS, Celgene, Janssen, Lilly, MSD, Novartis, Sanofi, UCB, Roche, and Pfizer, lain Mclnnes Grant/research support from: AstraZeneca, Celgene, Compugen, Novartis, Roche, UCB Pharma, Consultant for: AbbVie, Celgene, Galvani, Lilly, Novartis, Pfizer, UCB Pharma, Thomas Otto: None declared, Stefano Alivernini Speakers bureau: BMS, Mariola Kurowska-Stolarska: None declared

DOI: 10.1136/annrheumdis-2019-eular.7631

\section{OP0221 OLIGOMERIC S100A4 INDUCES MONOCYTE INNATE IMMUNE MEMORY}

Emmanuel Karouzakis ${ }^{1}$, Agnieszka Pajak ${ }^{1}$, Niels Riksen ${ }^{2}$, Leo Joosten², Mihai Netea ${ }^{2}$, Esther Lutgens ${ }^{3}$, Eric Stroes ${ }^{3}$, Adrian Ciurea ${ }^{1}$, Oliver Distler ${ }^{1}$, Mariam Grigorian ${ }^{4}$, Michel Neidhart ${ }^{1} .{ }^{1}$ University Hospital Zurich, Zurich, Switzerland; ${ }^{2}$ Radboud University Medical Center, Nijmegen, Netherlands; ${ }^{3}$ Academic Medical Center, Amsterdam, Netherlands; ${ }^{4}$ University of Copenhagen, Copenhagen, Denmark

Background: Trained immunity is a process of innate immune memory in which a primary stimulus such as beta-glucan can enhance the response of monocytes to secondary stimuli. The concept that specific damage associated molecular patterns (DAMPs) in rheumatoid arthritis (RA) could cause trained immunity which is involved in the disease pathogenesis has not been investigated so far. The oligomeric form of S100A4 (oS100A4) is a potent inducer of proinflammatory cytokines which is found in the plasma of patients with rheumatoid arthritis (RA).

Objectives: Aims are to investigate whether oS100A4 induces trained immunity in monocytes and characterize the molecular pathways involved in this process.

Methods: Monocytes were isolated from peripheral blood of healthy donors using anti-CD14 magnetic beads. To induce training, monocytes were stimulated with 2 $\mu \mathrm{g} / \mathrm{ml}$ of oS $100 \mathrm{~A} 4$ and $1 \mu \mathrm{g} / \mathrm{ml} \beta$-glucan for 24 hours $(n=8)$. We searched for differential gene expression by RNA sequencing in order to identify factors that play a role in the initial stages of trained immunity. On day 4, LPS $(10 \mathrm{ng} / \mathrm{ml})$ was added. After 24 hours, IL-6 and TNFalpha were measured in cell culture supernatants by ELISA. The training protocol was repeated in monocytes transfected with PRDM8 siRNA using Lipofectamine $(n=4)$. In addition, plasma levels of S100A4, CCL5 and IL- 6 were measured in a cohort of RA patients $(n=36)$ and healthy controls $(n=18)$ by ELISA and PRDM8 transcripts in RA peripheral blood monocytes were quantified by RT-PCR.

Results: Monocytes primed with oS100A4 showed increased releases of IL-6 and TNFalpha in response to a subsequent LPS stimulation. RNA-Seq revealed the differential expression of 902 genes upon oS100A4 and 667 upon beta-glucan (mean and median $>2$ fold, $p<0.01$ ). Among the differential genes, 601 were upregulated in S100A4 and 447 in beta-glucan stimulated cells. Upregulated genes included chemokine/cytokine and epigenetic factors. When we compared the upregulated genes from o $100 \mathrm{~A} 4$ and beta-glucan stimulated cells, $83 \%$ of chemokines/cytokines and $50 \%$ epigenetic factors were identical. Interestingly, the histone methyltransferase PRDM8 was found to be a major regulator of proinflammatory mediators by both stimuli. siRNA knockdown of PRDM8 abolished the training effect of OS100A4 by decreasing the LPS induced release of IL- 6 and TNFalpha $(p<0.01)$. Furthermore, we analyzed a cohort of monocytes taken from RA patients. Higher PRDM8 transcription in RA monocytes was associated with increased plasma levels of CCL5 and IL-6 $(r=0.52$ and $0.55, p<0.01)$. RA patients in remission versus active patients showed significantly lower PRDM8 transcripts $(p<0.05)$.

Conclusion: Oligomeric S100A4 induced trained immunity in monocytes similarly to beta-glucan. PRDM8 histone methyltransferase is involved in this process that appears to be activated in monocytes of RA patients.

Disclosure of Interests: Emmanuel Karouzakis: None declared, Agnieszka Pajak: None declared, Niels Riksen: None declared, Leo Joosten: None declared, Mihai Netea: None declared, Esther Lutgens: None declared, Eric Stroes: None declared, Adrian Ciurea Consultant for: AbbVie, Celgene, Janssen-Cilag, MSD, Eli Lilly, Novartis, Pfizer, UCB, Speakers bureau: Abbvie, Celgene, JanssenCilag, MSD, Eli Lilly, Novartis, Pfizer, UCB, Oliver Distler Grant/research support from: Prof. Distler received research funding from Actelion, Bayer, Boehringer Ingelheim and Mitsubishi Tanabe to investigate potential treatments of scleroderma and its complications, Consultant for: Prof. Distler has/had consultancy relationship within the last 3 years with Actelion, AnaMar, Bayer, Boehringer Ingelheim, ChemomAb, espeRare foundation, Genentech/Roche, GSK, Inventiva, Italfarmaco, iQvia, Lilly, medac, Medlmmune, Mitsubishi Tanabe Pharma,
Pharmacyclics, Novartis, Pfizer, Sanofi, Serodapharm and UCB in the area of potential treatments of scleroderma and its complications. In addition, he had/has consultancy relationship within the last 3 years with A. Menarini, Amgen, Abbvie, GSK, Mepha, MSD, Pfizer and UCB in the field of arthritides and related disorders, Mariam Grigorian: None declared, Michel Neidhart: None declared DOI: 10.1136/annrheumdis-2019-eular.5675

FRIDAY, 14 JUNE 2019

\section{Seeing is believing: nanotechnologies in tissue imaging}

\begin{tabular}{|l|l}
\hline OP0222 & STUDY OF VERTEBRAL FRACTURE PREVALENCE \\
AND SCANOGRAPHIC BONE ATTENUATION \\
COEFFICIENT (SBAC-L1) IN PATIENTS WITH \\
RHEUMATOID ARTHRITIS AND ANKYLOSING \\
SPONDYLITIS VS. CONTROLS
\end{tabular}

Marine Fauny ${ }^{1 *}$, Eliane Albuisson ${ }^{2}$, Elodie Bauer ${ }^{1}$, Julia Perrier Cornet ${ }^{1}$, Isabelle Chary Valckenaere ${ }^{1}$, Damien Loeuille ${ }^{1}{ }^{1}$ CHRU Nancy, Rheumatology, Vandoeuvre les Nancy, France; ${ }^{2} \mathrm{CHRU}$ Nancy, Vandoeuvre les Nancy, France

Background: Osteoporosis is a common disease whose prognosis can be seriously impacted by the development of fractures that lead to functional limitations and may even have life-threatening sequelae. This disease is often underscreened, especially in at-risk populations that require multidisciplinary care such as patients with rheumatoid arthritis (RA) and ankylosing spondylitis (AS) $[1,2,3,4,5,6]$. Moreover, a recent study showed that the scanographic bone attenuation coefficient of the first lumbar vertebra (SBAC-L1) with a threshold at 145 Hounsfield Units (HU) identified $96.6 \%$ of patients in the general population with a vertebral fracture (VF), whereas DEXA (with a T-score $\leq-2,5$ ) identified only $39 \%$ of these patients [7].

Objectives: The aim of the study was to identify the prevalence of vertebral fractures (VFs) and to measure the scanographic bone attenuation coefficient of the first lumbar vertebra (SBAC-L1) based on CT-scan examinations of patients with rheumatoid arthritis (RA), patients with ankylosing spondylitis (AS) and in a control group.

Methods: This monocentric and retrospective study included patients who were evaluated between 2009 and 2017 with a diagnosis of RA based on the ACR/ EULAR criteria, those with a diagnosis of AS based on the New-York criteria, and a RA-matched control group. All of the patients received a CT-scan. The osteoporosis risk factors, data from dual energy X-ray absorptiometry (DEXA) and clinical characteristics were collected. VFs were determined via CT-scans according to the Genant classification, and the SBAC-L1 was measured in Hounsfield units (HU). SBAC-L1 $\leq 145 \mathrm{HU}$ (fracture threshold) defined patients at risk of VFs.

Results: A total of 244 patients were included (105 RA, 83 AS, 56 controls). The AS group was younger and primarily consisted of males. Of the 4,365 vertebrae studied, 66 osteoporotic VFs were found in 36 patients: 18 (17.1\%) patients with RA, $13(15.7 \%)$ patients with AS and $5(8.9 \%)$ controls. The SBAC-L1 was 142.2 $( \pm 48.4) \mathrm{HU}$ for the RA group and $142.8( \pm 48.2)$ for the AS group, both of which were significantly lower than that of the control group $(161.8( \pm 42.7) \mathrm{HU})$. Of the 36 patients with VFs and rheumatism, $28 \%$ had a T-score $\leq-2.5 \mathrm{SD}$, and $71.4 \%$ had a SBAC-L1 $\leq 145 \mathrm{HU}$. A T-score $\leq-2.5 \mathrm{SD}$ and a SBAC-L1 $\leq 145 \mathrm{HU}$ were associated with the presence of a VF $(\mathrm{OR}=2.35[\mathrm{C} 195 \%: 1.12-4.92]$ and 2.06 [CI95\%: 1.04-4.10]), respectively.

Conclusion: The SBAC-L1 was significantly lower in the RA and AS groups than in the control group. Furthermore, SBAC-L1 $\leq 145 \mathrm{HU}$ was associated with a higher risk of VFs, with an odds ratio similar to that of a DEXA.

\section{REFERENCES:}

[1] Toledano E. Reumatol Clin. 2012 Nov-Dec;8(6):334-41.

[2] Dougado M. Ann Rheum Dis. 2014;73:62-8.

[3] McKeown E. Rheumatol Oxf Engl. 2012;51:1662-9.

[4] Van der Weijden MA. Clin Rheumatol. 2012 Nov;31(11):1529-35.

[5] Ghozlani I. Bone. 2009 May;44(5):772-6.

[6] Ardizzone M. Rev Med Interne. 2006 May;27(5):392-9.

[7] Pickhardt PJ. Ann Intern Med. 2013;158(8):588-95.

Disclosure of Interests: None declared DOI: 10.1136/annrheumdis-2019-eular.305 